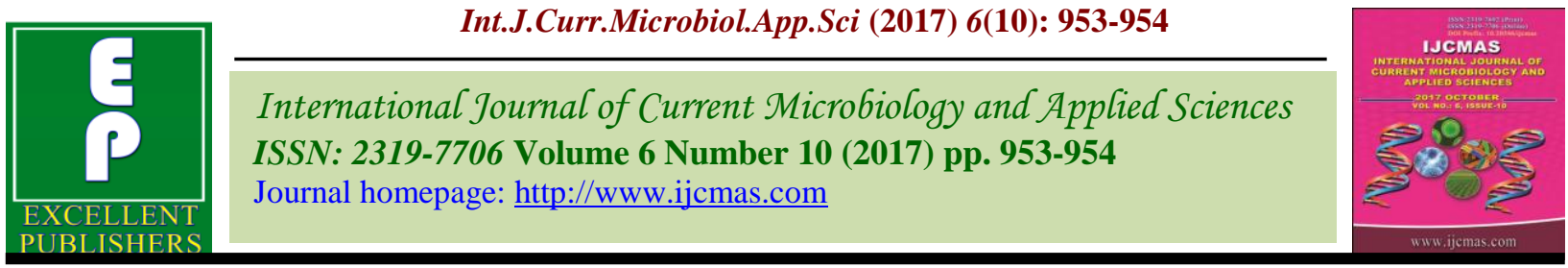

Case Study

https://doi.org/10.20546/ijcmas.2017.610.114

\title{
Detection of Pneumocystis jiroveci from a Gastric Aspirate Sample in a 3 Months Old HIV Positive Child - A Case Report
}

\author{
G. Dhaka*, Y. Rai and B.L. Sherwal \\ Department of Microbiology, Lady Hardinge Medical College \& Associated Hospitals, \\ New Delhi, India \\ *Corresponding author
}

A B S T R A C T

\begin{tabular}{|l|}
\hline $\begin{array}{l}\text { Ke y w or d s } \\
\text { Infections, HIV, } \\
\text { Report, Child. }\end{array}$ \\
\hline Article Info \\
\hline $\begin{array}{l}\text { Accepted: } \\
\text { 10 September } 2017 \\
\text { Available Online: } \\
10 \text { October } 2017\end{array}$ \\
\hline
\end{tabular}

Opportunistic infections are one of the major concerns in patients suffering from AIDS. If proper care is not taken, diagnosis of such infections is often missed which adds to increased morbidity of such patients. This case report highlights the importance of simple diagnostic methods in diagnosis of Pneumocystis jiroveci infection in children.

\section{Introduction}

AIDS was first recognized in the United States in the summer of 1981, when the U.S. Centre for Disease Control and Prevention (CDC) reported the unexplained occurrence of Pneumocystis jiroveci (formerly P. carinii) pneumonia in five previously healthy homosexual men in Los Angeles and of Kaposi's sarcoma (KS) with or without $P$. jiroveci pneumonia in 26 previously healthy homosexual men in New York and Los Angeles. But in India, the spectrum of opportunistic infections (OIs) is quite different from the western countries. Pneumocystis jiroveci is rarely documented in patients with AIDS $^{1}$. Initially thought to be a protozoon, Pneumocystis jiroveci has now been reclassified as a fungus ${ }^{2}$ which makes the role of fungi in causing opportunistic infections in HIV patients even more important. Early in the HIV epidemic, the principal risk factor for development of HIVrelated Pneumocystis jiroveci infection was established to be a reduced CD4 cell count. Data from the Multicentre AIDS Cohort Study (MACS) ${ }^{3}$ showed that the risk of Pneumocystis jiroveci Pneumonia was markedly increased in patients with CD4 cell counts of less than 200 cells $/ \mathrm{mm}^{3}$.

In the post prophylaxis era, patients with Pneumocystis jiroveci Pneumonia usually have severe immunosuppression. In one series of patients receiving care at an urban hospital $^{4}$, the median CD4 cell count for a first-time case of PCP was 36 cells $/ \mathrm{mm}^{3}$; for a recurrent case, it was 10 cells $/ \mathrm{mm}^{3}$. Care 
providers need to be aware that $\mathrm{PCP}$ remains a frequent sentinel opportunistic infection for patients who are not aware they are HIV positive and that this is also a risk factor for severe disease.

\section{Case Report}

We report a case of an HIV positive boy aged 3 months who presented to the tertiary care hospital with fever, cough, oral thrush and hepatosplenomegaly. He was provisionally diagnosed with pneumonia and a bronchoalveolar lavage (BAL) sample was taken for bacterial and fungal culture. Microscopic examination of the BAL sample did not show anypus cells or microorganisms.

The chest $x$-ray showed a diffuse, fine, reticular opacification. As the patient was very young, sputum sample was almost impossible to collect. So, a gastric aspirate (GA) was sent for detecting acid fast bacilli (AFB) and for Pneumocystis jiroveci. The AFB stain and culture came out to be negative.

The GA was stained with Giemsa stain for detection of cysts and trophozoites of Pneumocystis jiroveci. On examining the Giemsa stain, trophozoite $(2-4 \mu \mathrm{M})$ with blue nucleolus and pink cytoplasm in mass shape near each other were noted indicating the presence of Pneumocystis jiroveci infection. The patient was then put on TrimethoprimSulfamethoxazole and he recovered from the infection completely.

This case report highlights the importance of looking out for OIs such as Pneumocystis jiroveci in HIV positive patients. Even though in India, low rates of infection with
Pneumocystis jiroveci (0.7 - $7.0 \%)$ have been reported $^{5-8}$, this OI should not be ignored as a simple procedure as Giemsa stain can help in diagnosis of this disease.

\section{References}

Banerjee, U., Progress in diagnosis of opportunistic infections in HIV/AIDS. Indian JMed Res 2005; 121: 395-406

Edman, J.C., Kovacs JA, Masur H, Swati DV and Elwood HJ: Ribosomal RNA sequences shows Pneumocystis carinii to be a member of the fungi, Nature; 334:519, 1998

Gothi, D., Joshi JM. Clinical and laboratory observations of TB in a Mumbai (India) Clinic. Post Grad Med J 2004; 80: 97-100

Kumarasamy, N., Solomon S, Flanigan TP, Hemalatha R, Thyagarajan SP, Mayer KH. Natural history of human immunodeficiency virus disease in southern India. Clin Inf Dis 2003; 36: 7985

Lanjewar, D.N., Duggal R. Pulmonary pathology in patients with AIDS: an autopsy study from Mumbai. HIV Med 2001; 2: 266-71

Moore, R.D., Chaisson RE. Natural history of opportunistic disease in an HIV-infected urban clinical cohort. Ann Intern Med. 1996; 124:633-642

Phair, J., Munoz A, Detels R, et al., The risk of Pneumocystis carinii pneumonia among men infected with human immunodeficiency virus type 1 . Multicentre AIDS Cohort Study Group. N Engl J Med. 1990; 322:161-165

Rupali, P., Abraham OC, Zachariah A, Subramanian S, Mathai D. Aetiology of prolonged fever in antiretroviral naive human immunodeficiency virus-infected adults. Natl Med J India 2003; 16: 193-9.

\section{How to cite this article:}

Dhaka, G., Y. Rai and Sherwal, B.L. 2017. Detection of Pneumocystis jiroveci from a Gastric Aspirate Sample in a 3 Months Old HIV Positive Child - A Case Report. Int.J.Curr.Microbiol.App.Sci. 6(10): 953-954. doi: https://doi.org/10.20546/ijcmas.2017.610.114 